\title{
MÉTODOS PARA ESTIMAR O VOLUME DE FUSTES E GALHOS NA FLORESTA NACIONAL DO TAPAJÓS ${ }^{1}$
}

Renato Bezerra da Silva Ribeiro ${ }^{2 *}$, João Ricardo Vasconcellos Gama ${ }^{3}$, Agostinho Lopes de Souza ${ }^{4}$, Hélio

Garcia Leite ${ }^{4}$, Carlos Pedro Boechat Soares ${ }^{4}$ e Gilson Fernandes da Silva ${ }^{5}$

\footnotetext{
${ }^{1}$ Recebido em 09.04.2014 aceito para publicação em 20.11.2015.

${ }^{2}$ Universidade Federal do Oeste do Pará, Instituto de Biodiversidade e Florestas, Santarém, PA - Brasil. E-mail: $<$ florestalrenatoribeiro@gmail.com>.

${ }^{3}$ Universidade Federal do Oeste do Pará, Instituto de Biodiversidade e Florestas - IBEF, Santarem, PA - Brasil. E-mail: <jrvgama@gmail.com>>.

${ }^{4}$ Universidade Federal de Viçosa, Centro de Ciências Agrárias, Departamento de Engenharia Florestal, Viçosa, MG - Brasil. E-mail:<alsouzaa@gmail.com>,<hgleite@gmail.com>e <csoares@ufv.br>.

${ }_{5}^{5}$ Universidade Federal do Espírito Santo, Centro de Ciências Agrárias, Alegre, ES - Brasil. E-mail: <fernandes5012@gmail.com>.

*Autor para correspondência.
}

\begin{abstract}
RESUMO - Objetivou-se aplicar e avaliar métodos para estimar múltiplos volumes em uma Área de Manejo Comunitário, localizada na Floresta Nacional do Tapajós. Foram cubadas, rigorosamente, 516 árvores-amostra de 21 espécies comerciais, todas com $50 \mathrm{~cm} \geq$ dap $<160 \mathrm{~cm}$. Utilizaram-se o modelo único para múltiplos volumes (análise de regressão) proposto por Leite et al. (1995) e redes neurais artificiais (RNA) para a estimativa do volume de fuste e galhos. Após os resultados preliminares usando o método de regressão, optou-se por separar os dados em três estratos, considerando a relação volume de galhos em razão do volume de fuste comercial. As equações geradas por estratos apresentaram melhoria nos ajustes, mas os resultados obtidos pela RNA foram melhores que os pelas equações de regressão.
\end{abstract}

Palavras-chave: Redes neurais; Uso múltiplo; Resíduos de colheita florestal.

\section{METHODS TO ESTIMATE THE VOLUME OF STEMS AND BRANCHES IN THE TAPAJÓS NATIONAL FOREST}

\begin{abstract}
The objective of this study was to apply and evaluate methods to estimate multiple volumes in a Community Management Area, located in the Tapajós National Forest. 516 sample-trees were rigorously scaled of 21 commercial species, all with $50 \mathrm{~cm} \geq \boldsymbol{d b h}<160 \mathrm{~cm}$. The unique model for multiple volumes (regression analysis) proposed by Leite et al. (1995) and Artificial Neural Networks (ANN) were used to estimate the volume of stem and branches. After preliminary results using the regression method, it was decided to stratify the data into three parts, considering the relationship between volume of branches and volume of commercial stem. The equations generated showed improvement in the adjustments. However, the results with ANN were better than the ones generated by regression equations.
\end{abstract}

Keywords: Neural networks; Multiple use; Forest residues. 


\section{INTRODUÇÃO}

A madeira em tora advinda dos fustes comerciais das árvores é a principal fonte de matéria-prima para as indústrias. Dessa forma, os resíduos, considerados as partes não aproveitáveis da colheita florestal, acabam sendo deixados na área de manejo ou colhidos e diretamente utilizados como carvão e lenha (SALMERON, 1980; MAGOSSI, 2007).

De fato, os resíduos gerados pelo manejo são muito importantes para o setor energético, mas quando se trata de Floresta Amazônica, onde predominam árvores de grande porte e espécies de alto valor comercial, os resíduos grossos poderiam ter utilidade mais nobre, como na produção de móveis e pequenos artefatos de madeira, agregando mais valor e aproveitando melhor o recurso florestal.

Diante disso, as empresas e, ou, os empreendimentos florestais teriam que avaliar o potencial desses resíduos, buscando maneiras de quantificar e estimar a produção volumétrica anual dessa matéria-prima. Para Borsoi et al. (2012), o volume de galhos (resíduos) também assume importância na obtenção de estimativas precisas da produtividade da floresta, principalmente quando se avaliam diferentes usos.

O processo para obter a estimativa do volume de galhos não é tarefa muito fácil, uma vez que eles não mantêm relação bem definida com a forma representada por sólidos geométricos conhecidos (CAMPOS; LEITE, 2006). Sobretudo, é necessário haver compatibilidade entre os volumes estimados do fuste mais galhos e o volume total, o que pode não ocorrer quando se utilizam equações independentes (CAMPOS; LEITE, 2006).

Campos et al. (2001), a partir do estudo de Leite et al. (1995), desenvolveram um modelo volumétrico único para vários produtos, baseado na expansão do modelo de Schumacher e Hall (1993). Nesse modelo, é possível obter o volume de galhos (resíduos), sem que haja a perda da consistência estatística ou compatibilidade na estimativa (CAMPOS; LEITE, 2006).

Outro método alternativo que vem sendo muito promissor em relação às técnicas de regressão e difundido atualmente no manejo dos recursos florestais é o uso de Redes Neurais Artificiais (BINOTI, 2012). Uma rede neural consiste num modelo computacional biologicamente inspirado, constituído de elementos de processamento simples, capaz de gerar respostas

Revista Árvore, Viçosa-MG, v.40, n.1, p.81-88, 2016 a determinado conjunto de dados, desde que ela seja treinada (BINOTI, 2012).

Na Floresta Nacional do Tapajós, os resíduos florestais serão utilizados na fabricação de móveis e pequenos artefatos de madeira. Essa iniciativa ocorre na Área de Manejo Florestal da Cooperativa Mista da Flona do Tapajós (COOMFLONA) e tem potencial para beneficiar os moradores da Unidade de Conservação, assim como na região Oeste do Pará.

Nesse contexto, os objetivos deste estudo foram aplicar e avaliar métodos para estimar os volumes de fuste e de galhos na Floresta Nacional do Tapajós, sendo baseados na expansão do modelo de Schumacher e Hall (LEITE et al., 1995) e outro baseado em Inteligência Artificial por meio de Redes Neurais Artificiais.

\section{MATERIAL E MÉTODOS}

\section{1. Área de Estudo}

Os dados da pesquisa foram oriundos da Área de Manejo Florestal da Cooperativa Mista da Flona do Tapajós (COOMFLONA), especificamente na Unidade de Produção Anual número 5 (UPA 5). Essa área fica localizada na Floresta Nacional do Tapajós, km 83 da BR 163, Município de Belterra, PA.

O clima da região, pela classificação de Köppen, é do tipo Ami, com temperatura média anual de 25,5 ${ }^{\circ} \mathrm{C}$ e umidade relativa média em torno de $90 \%$. A precipitação média anual é de $1.820 \mathrm{~mm}$, com grande incidência de chuvas no período de janeiro a maio (IBAMA, 2004). Segundo dados do Radambrasil (1976), a área de estudo se encontra na unidade morfoestrutural Planalto Tapajós-Xingu, cuja cota altimétrica varia entre 120 e 170 m. Os solos predominantes na Unidade são os Latossolos Amarelos Distróficos, solos profundos e com baixa capacidade de troca cationnica (RADAMBRASIL, 1976). AFloresta Nacional do Tapajós situa-se na zona de Floresta Ombrófila Densa, tipo de vegetação dominante no Norte do país (IBGE, 2012), caracterizado pelo domínio de árvores de grande porte sob regime de temperaturas elevadas e precipitações distribuídas ao longo do ano (IBAMA, 2004).

\subsection{Coleta de dados}

Foram cubados os fustes e galhos de 516 árvoresamostra, distribuídas em 21 espécies (Tabela 1), representando $75 \%$ da lista de espécies comercializadas 
pela COOMFLONA. Para a cubagem dos fustes, utilizou-se o método de Smalian e para os galhos, o método de Huber.

Todas as árvores-amostra tinham dap igual ou superior ao Diâmetro Mínimo de Corte (DMC) de 50 $\mathrm{cm}$ até o diâmetro de $160 \mathrm{~cm}$, com a maioria das árvores presentes nas classes de 65 a 85 .

O volume real dos galhos (resíduos) foi obtido com a fórmula de Huber, tendo como circunferência e comprimento mínimos de $63 \mathrm{~cm} \mathrm{e} 0,5 \mathrm{~m}$, respectivamente. Considerou-se como fuste comercial a porção do tronco entre a altura de corte até o ponto de aproveitamento máximo, não incluindo as ramificações na base da copa.

\subsection{Análise dos dados}

Foi investigado o emprego de uma variação do modelo volumétrico múltiplo proposto por Leite et al. (1995). Esse modelo originalmente foi utilizado para estimar volumes com casca e sem casca por árvore individual, sendo neste estudo adaptado para estimar o volume de fuste comercial e volume total (fuste comercial + galhos com diâmetro ? $20 \mathrm{~cm}$ ). O modelo é apresentado da seguinte forma:

$$
V=\beta_{0} d a p^{\beta_{1}} h^{\beta_{2}} e^{\left(-\beta_{3} \frac{T x}{d a p}\right)}+\varepsilon
$$

em que $\mathrm{V}=$ volume com casca, em $\mathrm{m}^{3}$; dap= diâmetro medido na altura de $1,30 \mathrm{~m}$, em $\mathrm{cm}$; $\mathrm{h}=$ altura comercial, em metros; $T x_{1}=0$ para volume de fuste comercial; e $T x_{1}=1$ para volume total, ambos em $\mathrm{m}^{3} ; \beta_{1}$ a $\beta_{3}=$ parâmetros do modelo; e $\varepsilon=$ erro aleatório, $\operatorname{com} \varepsilon \sim$ $\mathrm{N}\left(0, \sigma^{2}\right)$.

Após o ajuste do modelo único pelo método dos mínimos quadrados ordinários, foram realizados a análise gráfica dos resíduos e os cálculos de exatidão da equação. Os softwares utilizados foram o Statistica 12 (STATSOFT INC., 2015) e o Microsoft Excel 2010.

O software utilizado para o treinamento e aplicação das redes foi o Neuroforest $\AA$ (BINOTI, 2012). Foram treinadas redes neurais artificiais para estimar o volume do fuste comercial e de galhos, sendo essas redes do tipo Multilayer Perceptron (MLP), com três camadas: uma de entrada, uma intermediária e uma de saída. As variáveis de entrada foram a Unidade de Trabalho (11 unidades), a espécie ( 21 espécies), o dap, a altura comercial e uma variável dummy, sendo 0 para volume do fuste e 1 para volume de galhos. O algoritmo de

Tabela 1 - Lista de espécies e número de árvores-amostra por classe de diâmetro.

Table 1 - List of species and number of sample trees for diameter classes.

\begin{tabular}{|c|c|c|c|c|c|c|c|c|c|c|c|c|}
\hline \multirow[t]{2}{*}{ Espécie } & \multicolumn{11}{|c|}{ Centro de Classe de dap (cm) } & \multirow[t]{2}{*}{ Total } \\
\hline & 55 & 65 & 75 & 85 & 95 & 105 & 115 & 125 & 135 & 145 & 155 & \\
\hline Angelim-pedra & & & & & & 1 & 1 & & 1 & & & 3 \\
\hline Breu-amescla & & 1 & 2 & 2 & 1 & 1 & 2 & 2 & & 1 & & 12 \\
\hline Cedro-vermelho & & 1 & 2 & 1 & & 2 & & & & 1 & & 7 \\
\hline Fava-timborana & 1 & 2 & 3 & 3 & 1 & 1 & 1 & 1 & & & & 13 \\
\hline Fava-tucupi & & 6 & 4 & 4 & 2 & 3 & 1 & & & & & 20 \\
\hline Garapeira & & & & & 2 & 2 & 1 & 1 & & 1 & & 7 \\
\hline Goiabão & 5 & 10 & 4 & & & & & & & & & 19 \\
\hline Gombeira & & 3 & 2 & 1 & & & & & & & & 6 \\
\hline Ipê-roxo & & 1 & 6 & 11 & 10 & 10 & 11 & 3 & 1 & 2 & & 55 \\
\hline Itaúba & & & 2 & 3 & 1 & 2 & & & & & & 8 \\
\hline Jarana & 2 & 16 & 21 & 14 & 5 & 3 & 2 & 1 & 1 & & 1 & 66 \\
\hline Jatobá & & & & 3 & 2 & 4 & 4 & 2 & 1 & & & 16 \\
\hline Jutaí-mirim & & 1 & 4 & 2 & 1 & 1 & & & & & & 9 \\
\hline Louro-preto & & 4 & 1 & 1 & & & & & & & & 6 \\
\hline Louro-rosa & & 2 & 2 & 1 & 1 & & & & & & & 6 \\
\hline Maçaranduba & 3 & 19 & 30 & 27 & 19 & 8 & 2 & 1 & 1 & & & 110 \\
\hline Muiracatiara & & 2 & 6 & 9 & 6 & 2 & 2 & 2 & & & & 29 \\
\hline Sapucaia & & & & 1 & & & & & & 1 & & 2 \\
\hline Tatajuba & & & 1 & 2 & 2 & 2 & 1 & 2 & 2 & & & 12 \\
\hline Tauari & 2 & 13 & 26 & 26 & 19 & 11 & 2 & 1 & 1 & & & 101 \\
\hline Virola & 1 & 7 & 1 & & & & & & & & & 9 \\
\hline Total & 14 & 88 & 117 & 111 & 72 & 53 & 30 & 16 & 8 & 6 & 1 & 516 \\
\hline
\end{tabular}


treinamento utilizado foi o Resilient propagation (RPROP+). Inicialmente, foi testado o uso de18 neurônios na camada intermediária, definido pela aproximação de $(11+21+3) / 2$, sendo 11 unidades de trabalho +21 espécies +3 variáveis não categóricas. Porém, nessa análise preliminar, verificou-se que apenas três neurônios foram suficientes, sendo esse número mantido para a comparação dos resultados com aqueles obtidos pela regressão. A função de ativação utilizada para as camadas oculta e de saída foi a sigmoide. O critério de parada utilizado foi a combinação do erro médio e do número de ciclos, sendo estabelecido o limite de 0,0001 para o erro médio e 3.000 ciclos. O treinamento foi encerrado quando o primeiro desses critérios foi atingido.

\subsection{Avaliação dos métodos}

As estimativas do modelo único e da RNA para os volumes de fuste e total $(\hat{Y})$ foram avaliadas, em relação aos valores observados $(Y)$, por meio do coeficiente de correlação $\left(\mathrm{R}_{\hat{Y} Y}\right), \mathrm{S}_{y \cdot x} \%$ (análise de regressão) e análise gráfica e dos histogramas dos resíduos percentuais.

Para determinar a exatidão das estimativas, foram calculadas as estatísticas bias, bias \%, variância do erro, raiz quadrada do erro quadrático médio (RQEM) e raiz quadrada do erro quadrático médio, expresso em porcentagem da média (RQEM\%), sendo:

$$
\begin{aligned}
& \text { bias }=\frac{\sum_{i=1}^{n}\left(\hat{y}_{i}-y_{i}\right)}{n}, \text { bias } \%=100 \frac{\sum_{i=1}^{n}\left(\hat{y}_{i}-y_{i}\right) / n}{\bar{Y}}, \quad \text { RQME }=\sqrt{\frac{\sum_{i=1}^{n}\left(\hat{y}_{i}-y_{i}\right)^{2}}{n}}, \\
& R Q M E \%=100 \frac{\sqrt{\sum_{i=1}^{n}\left(\hat{y}_{i}-y_{i}\right)^{2} /(n)}}{\bar{Y}} \text { eVariância }\left(\hat{y}_{i}-y_{i}\right)=\frac{\sum_{i=1}^{n}\left(\text { bias }-\left(\hat{y}_{i}-y_{i}\right)\right)^{2}}{n-1}
\end{aligned}
$$

\section{RESULTADOS}

Inicialmente, ajustou-se o modelo único múltiplo para os volumes de fuste comercial e total, resultando na equação geral de volume a seguir:

$$
\hat{V}=0,00014 \cdot \operatorname{dap}^{1,99698} \cdot h^{0,62851} \cdot\left(\exp \left(29,81472 \cdot \frac{T x_{1}}{\text { dap }}\right)\right)
$$

O coeficiente de correlação entre os valores observados e estimados pela equação (Rŷy) foi de 0,86 e o erro-padrão da estimativa ( $\mathrm{S} y, x \%$ ), igual a 30,06. Como possibilidade de melhorar as estimativas de precisão, foi realizada a estratificação dos dados, levando em consideração a proporção do volume de resíduo (galhos $\geq 20 \mathrm{~cm}$ ) com o volume de fuste.

Revista Árvore, Viçosa-MG, v.40, n.1, p.81-88, 2016
Os dados foram divididos em três estratos: árvores com volume de resíduo abaixo de $50 \%$, entre $50 \%$ e abaixo de $100 \%$ e igual ou superior a $100 \%$, e as porcentagens representaram a quantidade de volume de galhos grossos (resíduos) em função do volume de madeira em tora (fuste comercial).

Para cada um dos estratos, foram obtidas as equações a seguir:

Equação $1-\left(\frac{\text { Vresiduo }}{\text { Vfuste }}\right)<\mathbf{5 0 \%}$

$\hat{V}=0,00017 \cdot \operatorname{dap}^{1,88900} \cdot h^{0,73505} \cdot\left(\exp { }^{\left(22,67004 \cdot \frac{T x_{1}}{d a p}\right)}\right)$

Equação 2 - 50\% $>\left(\frac{\text { Vresiduo }}{\text { Vfuste }}\right)<\mathbf{1 0 0 \%}$

$\hat{V}=0,00003 \cdot d a p^{2,11009} \cdot h^{0,94874} \cdot\left(\exp ^{\left(46,19701 \cdot \frac{T x_{1}}{d a p}\right)}\right)$

Equação $3-\left(\frac{\text { Vresiduo }}{\text { Vfuste }}\right) \geq \mathbf{1 0 0 \%}$

$\hat{V}=7,21200 \times 10^{-8} \cdot d a p^{2,95467} \cdot h^{1,68226} \cdot\left(\exp ^{\left(80,48055 \cdot \frac{T x_{1}}{d a p}\right)}\right)$

Os coeficientes de correlação entre os valores observados e estimados pelas equações foram de 0,88 (equação 1), 0,87 (equação 2) e 0,97 (equação 3). O erro-padrão para as estimativas foram 25,66 (equação 1), 32,55 (equação 2) e 25,41 (equação 3).

Os gráficos de distribuição e histogramas dos resíduos foram gerados considerando o volume de fuste e o volume de galhos. O volume de galhos foi obtido pela diferença entre o volume de fuste e o volume total. As distribuições dos erros percentuais e dos resíduos para os volumes de fuste e de galhos estão apresentadas na Figura 1.

As redes neurais apresentaram coeficiente de correlação linear, entre volumes observados e volumes estimados, igual a 0,99 para os fustes e 0,92 para os galhos. Além disso, os volumes estimados estiveram mais próximos dos volumes observados em comparação com os resultados obtidos pelas análises feitas via regressão. Na Figura 2 são apresentados os resultados com as distribuições dos erros percentuais em relação aos volumes observados e estimados. 


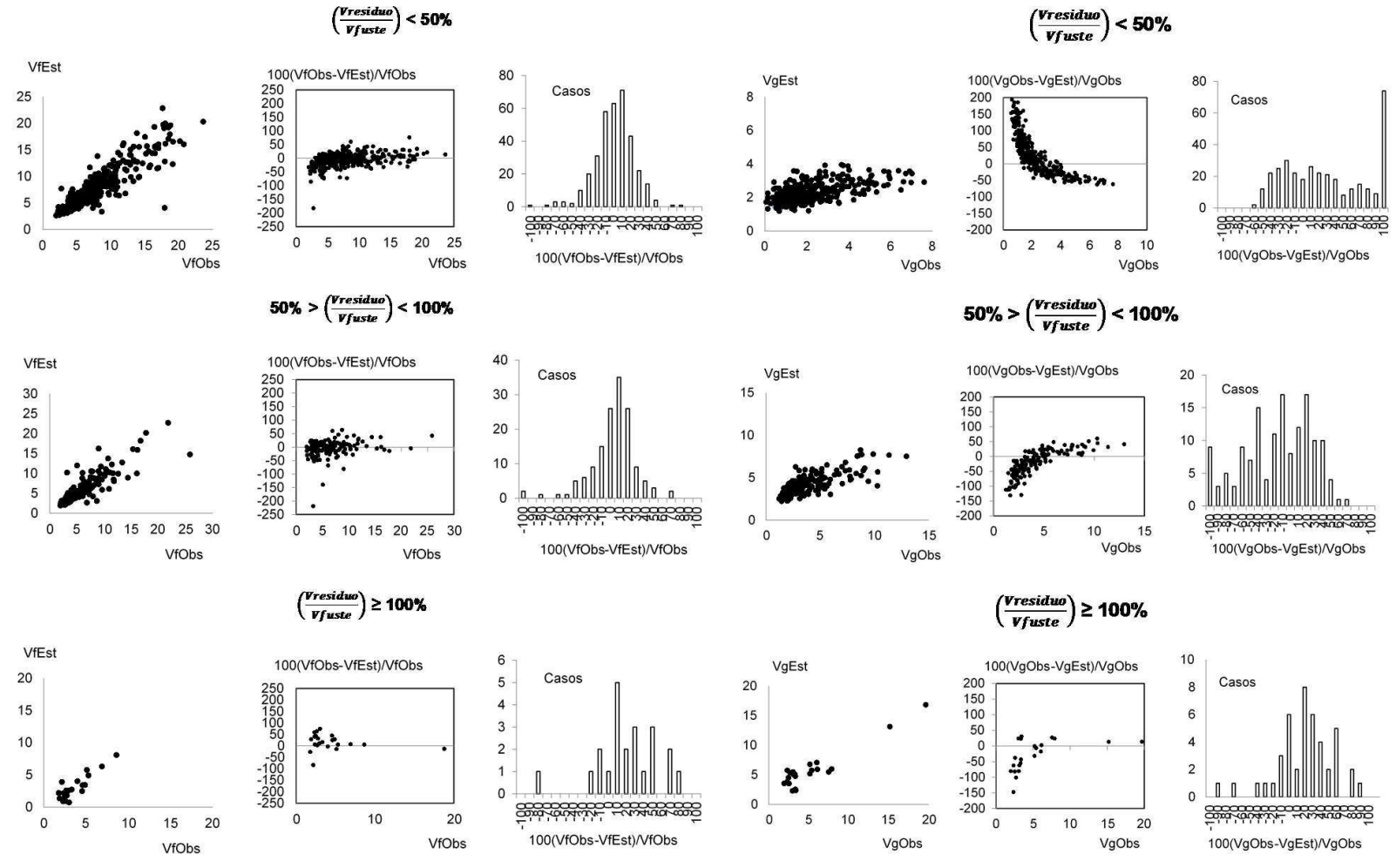

Figura 1 - Distribuição dos erros percentuais em relação ao volume observado, relação entre volumes estimados e observados e distribuição de frequência dos erros percentuais de volumes de fuste (A) e de galhos (B) utilizando análise de regressão.

Figure 1 -Distribution of percentage error according to the observed volume, relation between estimated and observed volumes and frequency distribution of the percentage errors of volumes of stem $(A)$ and branches $(B)$ using regression analysis.

Os resultados dos parâmetros de qualidade de ajustes das equações de regressão e da rede neural estão apresentados na Tabela 2. Os volumes estimados em função dos observados ficaram mais próximos da média, e o histograma indicou menor tendência de superestimação em relação aos resultados obtidos com as equações geradas via regressão.

\section{DISCUSSÃO}

Com base nos resultados, a estratificação dos dados apresentou melhoria nos parâmetros mais do que na utilização de uma equação única. No entanto, o uso de várias equações para determinado objetivo pode dificultar o planejamento de uma empresa ou empreendimento florestal.

Campos et al. (2001) estimaram os volumes de fuste comercial com casca e de galhos com diâmetros acima de $10 \mathrm{~cm}$ de povoamento misto em Minas Gerais. Eles obtiveram um coeficiente de correlação $\left(R_{\widehat{v} y}\right)$ de 0,98 e um coeficiente de variação de $38,08 \%$, cujos resultados foram considerados satisfatórios, levando em conta que os dados eram provenientes de um povoamento inequiâneo.

Os gráficos mostraram tendência de superestimação do volume de fuste (Figura 1A) nas três equações geradas, com a maioria dos dados com erros percentuais de $10 \%$. Essa tendência foi observada, principalmente, nos menores volumes.

As distribuições dos erros percentuais do volume de galhos foram irregulares e com forte tendência à superestimação (Figura 1B). A variação foi bem maior dos erros obtidos nos menores volumes.

Na distribuição dos resíduos pelo volume observado dos galhos, observou-se grande dispersão nos dados de ambos os métodos aplicados. Para Borsoi et al. (2012), 

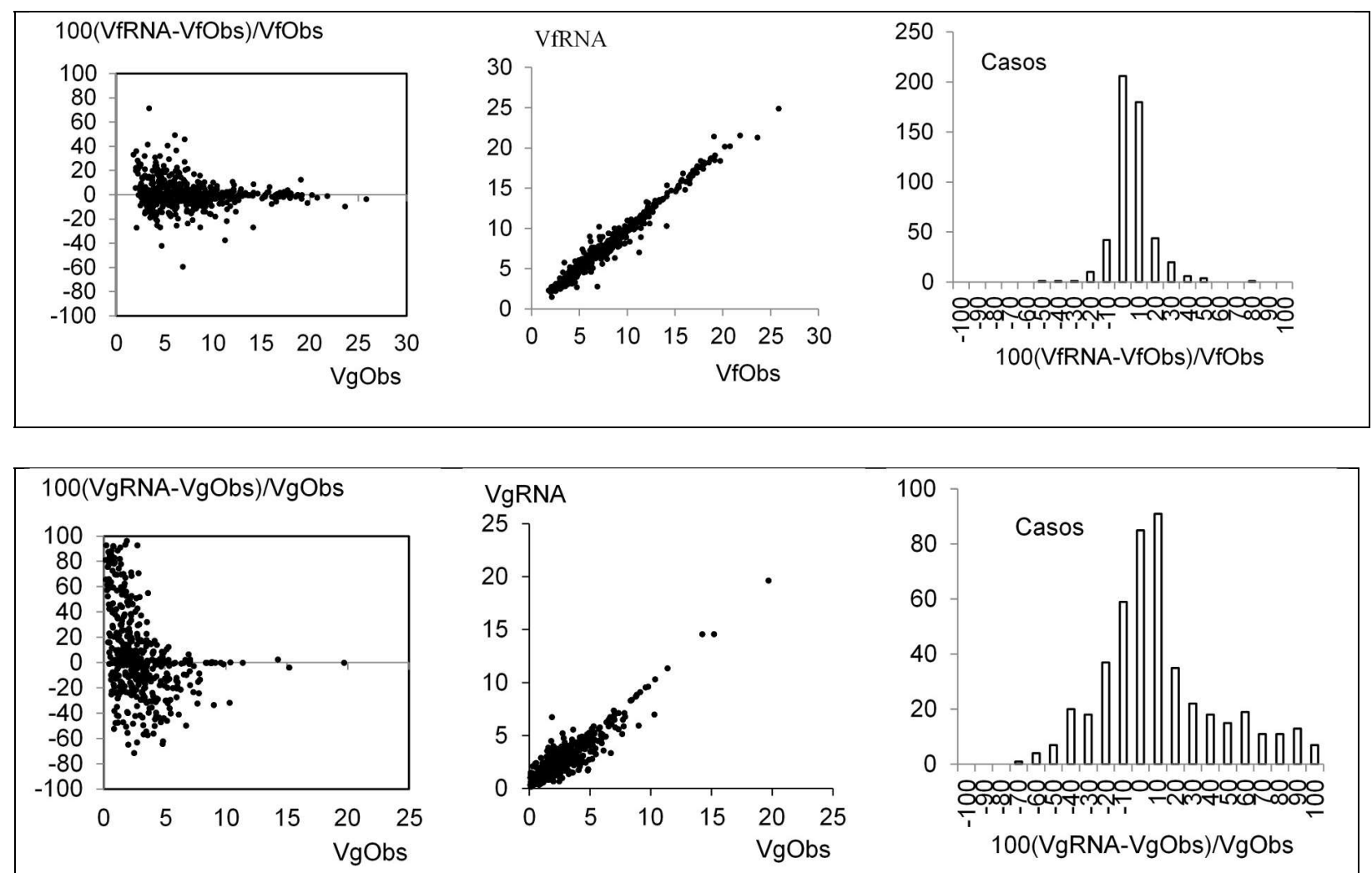

Figura 2 - Distribuição dos erros percentuais em relação ao volume observado, relação entre volumes estimados e observados e distribuição de frequência dos erros percentuais de volumes de fuste (A) e de galhos (B) pela RNA.

Figure 2 - Distribution of percentage errors for the observed volume, relation between estimated and observed volumes and frequency distribution of the percentage errors of volumes of stem (A) and branches (B) by ANN.

Tabela 2 - Resultado dos parâmetros de qualidade de ajuste das estimativas obtidas pelas equações de regressão e RNA dos volumes de fuste e galhos.

Table 2 - Result of the parameters of quality of adjustment for the estimations obtained by the regression equations and ANN for the stems and branches volumes.

\begin{tabular}{lccccc}
\hline \multicolumn{1}{c}{$\#$} & Bias & Bias\% & RQME & RQME\% & Variância (erro) \\
\hline Equação 1 (fuste) & $-0,023$ & $-0,290$ & 1,912 & 24,155 & 3,665 \\
Equação 1 (galhos) & 0,057 & 2,484 & 1,241 & 53,888 & 1,542 \\
Equação 2 (fuste) & $-0,093$ & $-1,472$ & 2,058 & 32,646 & 4,256 \\
Equação 2 (galhos) & 0,114 & 2,624 & 1,670 & 38,489 & 2,795 \\
Equação 3 (fuste) & $-0,494$ & $-12,92$ & 1,183 & 30,932 & 1,209 \\
Equação 3 (galhos) & 0,504 & 8,812 & 1,775 & 31,002 & 3,032 \\
RNA (fuste) & $-0,007$ & $-0,090$ & 0,712 & 9,540 & 0,509 \\
RNA (galhos) & 0,004 & 0,140 & 0,860 & 32,130 & 0,742 \\
\hline
\end{tabular}

isso pode ser explicado pelo número de espécies distintas ou por outros fatores (bióticos e abióticos).

Para Campos et al. (2001), também houve grande dispersão dos dados, de uma floresta primária em Minas Gerais, devido à variabilidade dos volumes

Revista Árvore, Viçosa-MG, v.40, n.1, p.81-88, 2016 de galhos das árvores, o que foi amenizado com a estratificação dos dados em diâmetros menores e maiores que $20 \mathrm{~cm}$.

Em uma Floresta Ombrófila Mista, Borsoi et al. (2012) agruparam as espécies em diferentes grupos 
de valor econômico, e os ajustes de volume de galhos se mostraram eficientes, apesar de ainda ter grande dispersão nos dados estimados pelas equações desenvolvidas no estudo.

De maneira geral, observou-se diferença nas estimativas entre as equações e as redes neurais artificiais, tendo as redes apresentado melhores resultados que as equações de regressão.

O treinamento de uma rede para estimar volume de fuste e outra rede para volume de galhos favoreceu a utilização das RNA, bem como a aplicação do método, na possibilidade de reduzir o tempo gasto com ajuste e avaliação do modelo volumétrico.

Schoeninger (2006) também obtiveram melhores resultados por meio das redes neurais artificiais, em relação aos empregos de modelos de regressão, para o estudo de biomassa e carbono em uma Floresta Ombrófila Densa no Estado de Santa Catarina. Ferraz (2012), estudando biomassa da parte aérea em povoamento inequiâneo no Município de Viçosa, Minas Gerais, obteve erros percentuais muito menores ao empregar a RNA, em relação ao uso da análise de regressão.

Este estudo indicou que o emprego de RNA é mais eficiente do que a análise de regressão para estimar o volume de fustes e de galhos na Floresta Nacional do Tapajós. Essa eficiência e a exatidão das estimativas de volume podem ser ainda maiores. Para isso, em outras pesquisas sobre estimação de volume que venham a ocorrer na referida floresta, ou em outros fragmentos ou povoamentos inequiâneos, devem ser feitos testes de parametrização e avaliação do possível ganho ao mudar a função de ativação sigmoide para outras, como a tangente hiperbólica. Testes de normalização e de equalização também poderão resultar em resultados ainda melhores ao estimar os volumes de fuste e de galhos.

\section{CONCLUSÃO}

- São escassos os estudos envolvendo estimativas simultâneas de fustes comerciais e galhos grossos, isto é, com diâmetros grandes na região amazônica.

- A estratificação dos dados por classes de tamanhos é eficiente para a melhoria dos ajustes quando se utiliza o método de regressão, mas a quantidade de equações pode dificultar a geração dos resultados desejados.
- A aplicação de redes neurais artificiais é mais eficiente para estimar volume comercial de fuste e galhos na Floresta Nacional do Tapajós do que a equação do modelo único para múltiplos volumes.

\section{AGRADECIMENTOS}

À Cooperativa Mista da Flona Tapajós, pela oportunidade e investimento na pesquisa; e ao Conselho Nacional de Desenvolvimento Científico e Tecnológico (CNPq), pela concessão de bolsa ao primeiro autor.

\section{REFERÊNCIAS}

BINOTI, M.L.M.S. Emprego de redes neurais artificiais em mensuração e manejo florestal. 2012. 138f. Tese (Doutorado em Ciência Florestal) - Universidade Federal de Viçosa, Viçosa, MG, 2012.

BORSOI, G.A.; MÜLLER, B.V.; BRENA, D.A. Equações de volume para galhos de espécies em diferentes grupos de valor econômico em uma Floresta Ombrófila Mista. Revista Ambiência, v.8, n.3, p.869-878, 2012.

CAMPOS, J.C.C.; LEITE, H.G.; SILVA, G.F.; SOARES, C.P.B.; CARNEIRO, J.A. Estimação de volumes do tronco e da copa de árvores de povoamentos mistos. Revista Árvore, v.25, n.2, p.223-230, 2001.

CAMPOS, J.C.C.; LEITE, H.G. Mensuração florestal: perguntas e respostas. 2.ed. Viçosa, MG: Universidade Federal de Viçosa, 2006. 470p.

FERRAZ, A.S. Estimação dos estoques de biomassa e carbono na parte aérea de um fragmento de floresta estacional semidecidual por meio de imagens de satélite IKONOS II. 2012. $103 \mathrm{f}$. Tese (Doutorado em Ciência Florestal) - Universidade Federal de Viçosa, Viçosa, MG, 2012.

INSTITUTO BRASILEIRO DE GEOGRAFIA E ESTATÍSTICA - IBGE. Manual técnico da vegetação brasileira. 2.ed. Rio de Janeiro: 2012.271p.

INSTITUTO BRASILEIRO DO MEIO AMBIENTE E DOS RECURSOS NATURAIS RENOVÁVEIS IBAMA. Floresta Nacional do Tapajós -

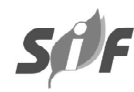

Revista Árvore, Viçosa-MG, v.40, n.1, p.81-88, 2016 
Plano de Manejo. Volume 1, Brasília, 2004. v.1. 580p.

LEITE, H.G.; GUIMARÃES, D.P.; CAMPOS, J.C.C. Descrição e emprego de um modelo para estimar múltiplos volumes de árvores. Revista Árvore, v.19, n.1, p.65-79, 1995.

MAgOSSI, D.C. A produção florestal e a industrialização de seus resíduos na região de Jaguariaíva - Paraná. 2007. 88f. Dissertação (Mestrado em Ciências Florestais) - Universidade Federal do Paraná, Curitiba, 2007.

RADAMBRASIL. Folha SA.21-Santarém: geologia, geormorfologia, pedologia, vegetação, uso potencial da terra. Rio de Janeiro: Ministério das Minas e Energia, 1976. 510p.
SALMERON, A. Pesquisa sobre mecanização florestal para abastecimento industrial de resíduo visando a produção de energia. Série Técnica IPEF, v. 1, n. 2, p. 1-12, 1980.

SCOLFORO, J.R.S. Mensuração florestal 2: volumetria. Lavras: ESAL/FAEPE, 1993.126p.

SCHOENINGER, E.R. Uso de redes neurais artificiais para mapeamento de biomassa e carbono orgânico no componente arbóreo de uma Floresta Ombrófila Densa. 2006. 146f. Tese (Doutorado em Ciências Florestais) Universidade Federal do Paraná, Curitiba, 2006.

STATSOFT INC. Statistica data analysis system version 12.0. Tulsa: 2015. 